\title{
Epidemiological, Clinical and Biological Characteristics of Patients with Chronic Hepatitis B Infection Followed-Up at the University Hospital of Conakry, Guinea
}

\section{Djenabou Diallo', Kadiatou Diallo, Alpha Mamadou Diallo², Mamadou Mansour Diallo², Thierno Amadou Wann1, Amadou Diouldé Doumbouya1, Ousmane Sow¹, Youssouf Baldé1, Alpha Amadou Sank Dillo ${ }^{1}$}

\author{
${ }^{1}$ Department of Internal Medicine, University Hospital of Donka, Conakry, Guinea \\ ${ }^{2}$ Department of Endocrinology, Diabetes and Metabolic Diseases, University Hospital of Donka, Conakry, Guinea \\ Email: djenaboutaran90@gmail.com
}

How to cite this paper: Diallo, D., Diallo, K., Diallo, A.M., Diallo, M.M., Wann, T.A., Doumbouya, A.D., Sow, O., Baldé, Y. and Dillo, A.A.S. (2020) Epidemiological, Clinical and Biological Characteristics of $\mathrm{Pa}$ tients with Chronic Hepatitis B Infection Followed-Up at the University Hospital of Conakry, Guinea. Open Journal of Gastroenterology, 10, 256-265.

https://doi.org/10.4236/ojgas.2020.1010025

Received: August 26, 2020

Accepted: October 17, 2020

Published: October 20, 2020

Copyright $\odot 2020$ by author(s) and Scientific Research Publishing Inc. This work is licensed under the Creative Commons Attribution International License (CC BY 4.0).

http://creativecommons.org/licenses/by/4.0/

\begin{abstract}
Introduction: Very little information is available in Guinea on chronic hepatitis $\mathrm{B}$ infections. The objective of this study was to describe the epidemiological, clinical and biological features of patients who are chronic carriers of the hepatitis B virus. Patients and Methods: This is a retrospective study carried out from January 2017 to May 2020, based on the medical records of patients seen via consultation or hospitalized with a record of positive HBs antigen for more than 6 months. Clinical and paraclinical data were collected and analyzed. Results: Seven hundred and sixteen patients with a mean age of $35.6 \pm$ 12.2 (sex ratio 2.05), were included. The HBs antigen was discovered incidentally in $36 \%$ of cases $(n=258)$. A history of dental care and surgical procedures was found in $46.3 \%(\mathrm{n}=290)$ and $21.1 \%(\mathrm{n}=138)$ of cases, respectively. The median value of ALAT enzymes was 34 (21 - 47) IU/L. HBeAg was positive in $20.8 \%(\mathrm{n}=55 / 265)$ of cases. The median B viral load was 458.5 ( 87 - 3827) IU/ml and $29 \%(\mathrm{n}=94)$ of patients had a viral load over $2000 \mathrm{IU} / \mathrm{ml}$. Anti-HCV antibody was present in $10.4 \%$ of cases $(\mathrm{n}=39 / 374)$. HIV serology was positive in $2.7 \%(n=8 / 298)$. A total of $19.4 \%(n=139)$ of the patients had cirrhosis and 4.5\% $(\mathrm{n}=32)$ had hepatocellular carcinoma. Conclusion: The discovery of chronic HBs antigen was mostly fortuitous in young sexually active men, some of whom were already at the stage of cirrhosis and hepatocellular carcinoma. The best prevention strategy against this infection remains early detection and vaccination.
\end{abstract}




\section{Keywords}

Viral Hepatitis B, Epidemiology, Clinical, Biology

\section{Introduction}

Hepatitis B virus (HBV) infection is a major public health condition affecting approximately 240 million people worldwide [1]. The natural history of HBV infection is variable, ranging from inactive carrier status to chronic hepatitis $B$, which can progress to cirrhosis and hepatocellular carcinoma [2]. Despite the existence of a preventive vaccine that is $95 \%$ effective, since 1982, hepatocellular carcinoma has been the second most deadly cancer in the world [3].

Management of chronic viral hepatitis B is costly, and prevention through screening and vaccination, either selected or generalized, remains the most effective strategy to reduce its incidence.

Sub-Saharan Africa is an area of high prevalence (8\% - 15\%) of HBV [4] [5] [6]. In Guinea, studies have been conducted on target populations. They have shown in prison settings, among people living with the acquired immunodeficiency virus and among diabetics, frequencies of $27.7 \%, 8 \%-9 \%$, and $8 \%$, respectively [7] [8] [9] [10].

However, no data on a large population of chronic HBsAg carriers have been published.

The objective of this study was to describe the epidemiological, clinical and biological aspects of patients who are chronic carriers of HBsAg.

\section{Patients and Methods}

\subsection{Setting}

We conducted a retrospective study in the Internal Medicine Department of the Conakry University Hospital, from January 2017 to March 2020.

\subsection{Population and Inclusion Criteria}

We included all patients followed in ambulatory or hospitalized who had a persistent positive HBsAg for more than 6 months (confirmed by ELISA method). Patients with a negative HBsAg control within 6 months of initial diagnosis, reclassified as acute hepatitis, were excluded from the study.

\subsection{Data Collection and Variables}

Data were collected from patients' medical consultation and hospitalization records on an existing survey form. The study variables were: Epidemiological (age, sex, place of residence, marital status, occupation, risk factors); Clinical (mode of discovery, history, clinical signs); Biological (haemoglobin, platelets, prothrombin levels, blood transaminases, total bilirubin, creatinine, alpha fetoprotein, albumin, $\mathrm{HBe}$ antigen, hepatitis $\mathrm{C}$ antibody, HIV antibody, viral load B, 
Fibrotest fibrosis score ${ }^{\star}$ ); ultrasound and CT scan.

The diagnosis of cirrhosis was based on clinical, ultrasound and Fibrotest* results, and that of hepatocellular carcinoma on the results of liver CT scan.

For the evaluation of hepatic fibrosis by Fibrotest* only the higher values were taken.

\subsection{Ethics and Deontology}

The study was approved by the Ethics Committee of the University Hospital Center of Conakry in accordance with the Declaration of Helsinki.

\subsection{Statistical Analysis}

Continuous variables were expressed as mean and standard deviation or median and interquartile range, while categorical variables were expressed as a percentage. Data were analyzed with EPI INFO software, version 3.5.4.

\section{Results}

A total of 716 patients aged $35.6 \pm 12.2$ years, ranging in age from 5 to 73 years were included. Population's sex ratio was 2.05. About half of the population (45\%) attended school in this study. According to marital status, most of the people $(68.3 \%)$ were married. The study population resided mainly in Conakry, the capital city, in 74.7 percent of cases. The discovery of chronic HBsAg carriage was fortuitous in $36 \%$ of cases, followed by the diagnosis of physical asthenia in $14.6 \%$. The main co-morbidities were dominated by hypertension in $6.42 \%$ of cases and diabetes in $4.32 \%$. The notion of alcohol consumption was found in 103 patients out of the 552 responders (18.7\%). Tobacco smoking was found in $16 \%$ of cases. These epidemiological characteristics are detailed in $\mathrm{Ta}$ ble 1 .

Risk factors were dominated by a history of dental care in $46.3 \%$ of cases, surgery in $21.1 \%$ of cases and scarification in $9.7 \%$ as shown in Figure 1.

The main clinical signs found were physical asthenia in $29.4 \%$ of cases (208/707), jaundice in $11.6 \%$ of cases $(77 / 665)$ and hepatomegaly in $9.8 \%(63 / 646)$. These results are detailed in Table 2.

The biological characteristics of the sample are presented in Table 3. HBeAg was positive in $20.8 \%$ of the patients $(55 / 265)$ and the mean B viral load was 441.5 of which $29 \%$ were above $2000 \mathrm{IU} / \mathrm{ml}$ at inclusion. The mean transaminase level of patients was $34 \mathrm{IU} / \mathrm{ml}(21-47)$ and the mean platelet level was $216,000 / \mathrm{mm}^{3}$, ranging from 169,000 to 275,000 . There was HIV-HBV co-infection in $2.7 \%(8 / 298)$ and HCV-HBV co-infection in 10.4\% (39/374).

Fibrotest $^{*}$ showed an absence of fibrosis (F0) in 58.2\% (110/189), minimal fibrosis F1 in $12.7 \%$ of cases (24/189) and significant fibrosis (F2-F3-F4) in 29\% of cases including 12 cases of cirrhosis (6.3\%).

Hepatocellular carcinoma was found in 32 patients (4.5\%), 20 (64\%) of whom had alpha fetoprotein levels greater than $400 \mathrm{IU} / \mathrm{ml}$. Liver ultrasound was normal in 
Table 1. Epidemiological characteristics of the study population.

\begin{tabular}{lc}
\hline \multicolumn{1}{c}{ Variables } & Characteristics \\
\hline Age mean \pm standard deviation & $35.59 \pm 12.15$ \\
Gender (male), n (\%) & $482(67.3)$ \\
Marital status n (\%) & $489(68.3)$ \\
- Married & $203(28.4)$ \\
- Single & $15(2)$ \\
- Widow/widower & $9(1.3)$ \\
- Divorced & \\
Residence (\%) & $535(74.7)$ \\
- Conakry (capital city) & $164(23)$ \\
- Inland & $17(2.3)$ \\
- Abroad & \\
Profession n (\%) & $161(22)$ \\
- Public officer & $122(17)$ \\
- Merchant & $107(15)$ \\
- Student & $77(11)$ \\
- Housewife & $59(8)$ \\
- Worker & $41(6)$ \\
- Health personnel & $34(5)$ \\
- Driver & $26(4)$ \\
- Military/Paramilitary & $89(12)$ \\
- Others &
\end{tabular}

Table 2. Clinical features of the population at the time of diagnosis of hepatitis B.

\begin{tabular}{lc}
\hline \multicolumn{1}{c}{ Variables } & Charactheristics \\
\hline Diagnostic circumstances n (\%) & $258(36)$ \\
Incidental screening & $105(14.6)$ \\
Asthenia & $91(12.7)$ \\
Flu-like symptoms & $77(10.7)$ \\
Icterus & $59(8.2)$ \\
Ascitic-edematous syndrome & $35(4.8)$ \\
Chronic hepatopathy & $30(4.1)$ \\
Blood giving & $61(8.5)$ \\
Others & \\
Comorbidities & $46(6.42)$ \\
Hypertension & $31(4.32)$ \\
Diabetes & $103 / 552(18.7)$ \\
Alcohol & $88 / 550(16)$ \\
Smoking & \\
Symptoms n/N (\%) & \\
Asthenia & $208 / 707(29.4)$ \\
Icterus & $77 / 665(11.6)$ \\
Hepatomegaly & $63 / 646(9.8)$ \\
Splenomegaly & $22 / 620(3.5)$ \\
Collateral venous circulation & $9 / 629(1.4)$ \\
Ascitic-edematous syndrome & $59 / 637(9.3)$ \\
Digestive haemorrhage & $7 / 585(1.2)$ \\
Hepatic encephalopathy & $5 / 638(0.8)$ \\
\hline & \\
\hline & \\
\hline
\end{tabular}


Table 3. Biological chatacteristics of the population at the time of diagnosis of hepatitis B.

\begin{tabular}{|c|c|}
\hline Variables & Mean $\pm \mathrm{SD} /$ Median $(\mathrm{Q} 1-\mathrm{Q} 3) / \mathrm{n} / \mathrm{N}(\%)$ \\
\hline Positive HBe antigen & $55 / 265(20.8)$ \\
\hline Anti-hepatitis $C$ virus antibodies & $39 / 374(10.4)$ \\
\hline HIV & $8 / 298(2.7)$ \\
\hline \multicolumn{2}{|l|}{ Initial hepatitis B viral load $(n=324)$} \\
\hline$\leq 2000 \mathrm{UI} / \mathrm{ml}$ & $230(71)$ \\
\hline$>2000 \mathrm{UI} / \mathrm{ml}$ & $94(29)$ \\
\hline \multicolumn{2}{|l|}{ Fibrotest fibrosis score } \\
\hline F0 & $110 / 189(58.2)$ \\
\hline $\mathrm{F} 1$ & $24 / 189(12.7)$ \\
\hline $\mathrm{F} 2$ & $32 / 189(16.9)$ \\
\hline F3 & $11 / 189(5.8)$ \\
\hline $\mathrm{F} 4$ & $12 / 189(6.3)$ \\
\hline Hemoglobin level in $\mathrm{g} / \mathrm{dl}(\mathrm{n}=465)$ & $12.7 \pm 2.42$ \\
\hline Blood platelet count $/ \mathrm{mm}^{3}(\mathrm{n}=337)$ & $216,000(169,000-275,000)$ \\
\hline Aspartate aminotransferase in IU/ml $(\mathrm{n}=431)$ & $30(21-43)$ \\
\hline Alanine aminotransferase $(\mathrm{n}=480)$ en UI/ml & $34(21-47)$ \\
\hline Albuminemia in $\mathrm{g} / \mathrm{l}(\mathrm{n}=129)$ & $38.8 \pm 13.7$ \\
\hline Total bilirubin in $\mathrm{mg} / \mathrm{l}(\mathrm{n}=275)$ & $13(7-20)$ \\
\hline Blood creatinine in micromole/l $(\mathrm{n}=263)$ & $82(63-96)$ \\
\hline \multicolumn{2}{|l|}{ Prothrombin level $(\mathrm{n}=219)$} \\
\hline$\geq 70 \%$ & $151(68.9)$ \\
\hline$<70 \%$ & $68(31.1)$ \\
\hline \multicolumn{2}{|l|}{ Alpha fetoprotein level $(\mathrm{n}=294)$} \\
\hline$\leq 10 \mathrm{UI} / \mathrm{ml}$ & $197(67)$ \\
\hline$>10$ and $\leq 400 \mathrm{UI} / \mathrm{ml}$ & $67(26.2)$ \\
\hline$>400 \mathrm{UI} / \mathrm{ml}$ & $20(6.8)$ \\
\hline
\end{tabular}

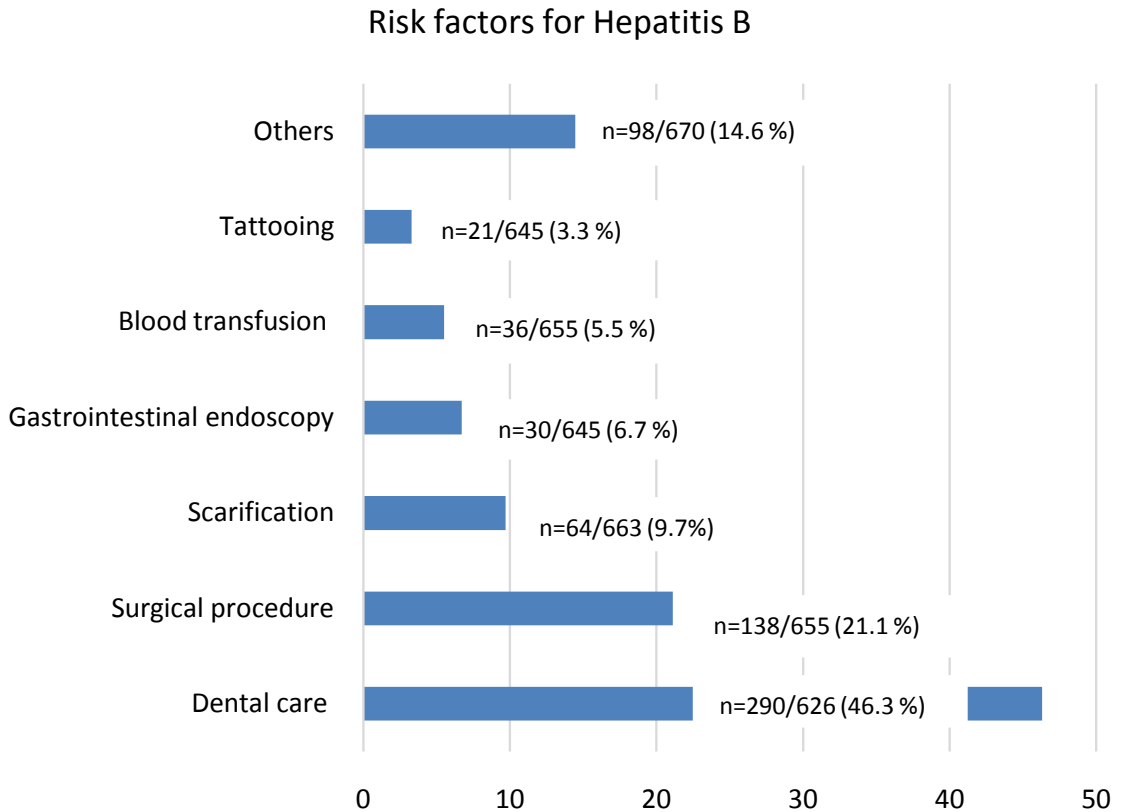

Figure 1. Risk factors for hepatitis B in the study population. 
223 patients (55.2\%); there was homogeneous hepatomegaly in 62 patients (15.3\%), dysmorphic liver in 53 patients (13.1\%), suspicious hepatocellular carcinoma nodules in 35 patients $(8.7 \%)$, hepatic steatosis in 28 patients $(6.9 \%)$ and atrophic liver in 3 patients $(0.7 \%)$.

\section{Discussion}

This study involved a population of 716 patients, the majority of them were young adults between the ages of $27-42$. These results are consistent with those of most African studies [6] [7] [8] [9] [11].

Men were the most affected by chronic hepatitis $B$ with a sex ratio of 2.05 . This result is consistent with other African studies [6] [12] [13]. This predominance could be explained by the male tropism of the hepatitis B virus as described in the literature [14].

The scholarized population was the most represented among the hepatitis B carriers in this study, which could be linked to the fact that this group is more accessible to sensitization and by ricochet to screening.

The diagnosis of viral hepatitis B made incidentally in $37.7 \%$ of cases is consistent with data from the African literature [13] [15] [16]. It's discovery during systematic screening seems to be related to the silent evolution of chronic HBsAg, a frequent mode of revelation in sub-Saharan Africa.

There was a notion of alcohol consumption in $18.7 \%$ of our study population, a rate higher than the one reported in the Prolifica study but lower by half than the one reported in a study conducted in Pointe Noire, Congo [11] [15]. Since alcohol is also hepatotoxic, its consumption increase the risk of progression to hepatic complications.

The main co-morbidities found were hypertension found in 46 patients (6.42\%) and diabetes in 31 patients (4.32\%). The Beninese study found $16.1 \%$ of hypertension and $4.3 \%$ of diabetes [6].

The main risk factors were dental care in $46.3 \%$ and surgical procedures in $21.1 \%$. Kpossou et al. found scarification as the main risk factor in $37.8 \%$ of cases and non-medical circumcision in $22 \%$ of cases, surgery as a risk factor was found in $19.5 \%$.

Oumar Traoré in his dissertation had also found dental care as the first risk factor in $15.6 \%$, followed by tattoos in $11 \%$ and surgery in $7.1 \%$ of cases.

Dental care is described as a risk factor for HBV transmission in literature, but the causes of this transmission vary from one study to another. A study published by Rimland et al. found that contamination was primarily caused by a HBVpositive dentist who did not wear gloves during the procedure [17].

According to the 1995 study by Arboleda et al., patients treated by nonprofessional dentists were 2.6 times more likely to be infected with HBV than those who received dental treatment by trained professionals [18]. However, surgery has been described as the medical profession associated with the higher risk of transmission of HBV [19]. 
The $2.7 \%$ rate of HBV-HIV viral co-infection is far lower than previously reported rates in Guinea in target populations with HIV infection [8] [9]. However, this rate is comparable to those reported in the Prolifica study and in Congo with $3.3 \%$ and $1.5 \%$ respectively [11] [15]. Another study performed in Tunisia found a higher proportion (5.64\%) of HBV and HIV co-infection [20].

VHB and HIV co-infection is common, due to the fact that these two viruses share the same modes of transmission and risk factors. This co-infection is a pejorative factor in the prognosis because HIV infection accelerates the progression of hepatitis B to cirrhosis and hepatocellular carcinoma.

In addition, viral $\mathrm{C}$ co-infection was found in $10.4 \%$ of cases, a result higher than those reported by most African studies [6] [11] [13] [21].

In our series, $20.8 \%$ of patients were $\mathrm{HBeAg}$ positive, a rate higher than the one reported in the Prolifica study where the positivity of HBeAg ranged from $3.3 \%$ to $7.9 \%$, but close to the $15.2 \%$ found by Lawson et al. in Ivory Coast [11] [22].

Less than half of the patients were able to perform the viral load assay, which is the essential marker for therapeutic indication and monitoring. In Guinea, as in most African countries, management remains a major difficulty in the absence of healthcare coverage.

Of the 189 patients who were able to perform the markers for evaluating hepatic fibrosis (Fibrotest ${ }^{*}$ ), 28.4\% had significant fibrosis, of which $6.3 \%$ had cirrhosis.

According to the clinical signs, liver ultrasound and Fibrotest ${ }^{*}$ we found $19.4 \%$ cirrhosis at diagnosis. This result is similar to the one reported by Diallo S. et al. in Senegal (22.11\%) [16] but lower than the one found by Lawson et al. in the Ivory Coast (42.4\%) [22]. Among the population with cirrhosis, $8.7 \%$ were at the stage of hepatocellular carcinoma with an AFP rate $>400 \mathrm{IU} / \mathrm{ml}$ found in $64 \%$ of cases. This high rate of cirrhosis and hepatocellular carcinoma shows the lack of early diagnosis and treatment of this viral B infection in our context.

The progression of hepatic fibrosis to cirrhosis and hepatocellular carcinoma is due to the persistence of viral replication [23].

In this population, 166 patients were eligible for antiviral treatment according to EASL recommendations [3]. The main drug used was Tenofovir because of its high resistance barrier and its availability in our country despite its high cost.

The study had some limitations that should be pointed out. First, there was the lack of a registry in the Department to assess the weight of viral hepatitis B. Secondly, the lack of social security coverage was a barrier to perform the biological exams required for an appropriate follow-up. Indeed, only half of the patients performed the viral load while the evaluation of fibrosis was possible in a quarter of the patients.

However, this study was a descriptive approach to chronic hepatitis B in a large hospital sample that provided insight into the epidemiological, clinical and biological characteristics in an urban setting in a low-income country. 


\section{Conclusions}

Chronic viral hepatitis B predominantly affected young adult males in this study, with a fortuitous finding in most cases. The main risk factors found were dental care and surgical procedures.

The high proportion of complications, especially from cirrhosis and hepatocellular carcinoma, found immediately upon diagnosis, is an indicator of insidious evolution and delay in the diagnosis of this infection in our context. Moreover, access to diagnostic and therapeutic tools remains a major challenge. Therefore, awareness on screening and vaccination is the best strategy to reduce hepatitis B infection.

\section{Authors' Contribution}

Djenabou Diallo coordinated the study, developed the protocol, collected data, participated in data analysis, structuring and writing the article (senior editor).

Kadiatou Diallo collected the data, reviewed the article and provided critique to improve the content.

Alpha Mamadou Diallo participated in the development of the protocol, analyzed the data, and participated in the structuring and writing of the article.

Mamadou Mansour Diallo and Thierno Amadou Wann took part in the elaboration of the protocol, reviewed the article and provided critiques to improve the content of the article.

Alpha Amadou Sank Diallo reviewed the article and provided critiques to improve the content.

Amadou Diouldé Doumbouya, Ousmane Sow, Youssouf Baldé collected the data and reviewed the article.

\section{Conflicts of Interest}

The authors declare no conflicts of interest regarding the publication of this paper.

\section{References}

[1] Schweitze, A., Horn, J., Mikolajczyk, R.T., Krause, G. and Ott, J.J. (2015) Estimations of Worldwide Prevalence of Chronic Hepatitis B Virus Infection: A Systematic Review of Data Published between 1965 and 2013. The Lancet, 386, 1546-1555 https://doi.org/10.1016/S0140-6736(15)61412-X

[2] European Association for the Study of the L (2017) EASL 2017 Clinical Practice Guidelines on the Management of Hepatitis B Virus Infection. Journal of Hepatology, 67, 370-398.

[3] Ferlay, J., Soerjomataram, I., Dikshit, R., Eser, S., Mathers, C., Rebelo, M., Parkin, D.M., Forman, D. and Bray, F. (2015) Cancer Incidence and Mortality Worldwide: Sources, Methods and Major Patterns in GLOBOCAN 2012. International Journal of Cancer, 136, 359-386. https://doi.org/10.1002/ijc.29210

[4] Servais, A.F., Eloumou, B., Attia, K.A., et al. (2013) Evaluation of Immunization Status against Hepatitis B of Paramedical Staff in University Hospital of Yopougon in Côte-d'Ivoire. Revue de Médecine et de Pharmacie, 3, 346-353. 
[5] Assi, C., Ouattara, A., Allah-Kouadio, E., Diakite, M., Koné, S., Lohoues Kouacou, M.J. and Camara, B.M. (2011) Vaccination Coverage against the Hepatitis B and Prevalence of HBsAg: Cross-Sectional Study of 592 Persons in Abidjan. Clinics and Research in Hepatology and Gastroenterology, 35, 506-507. https://doi.org/10.1016/j.clinre.2011.02.010

[6] Kpossou, A.R., Sehounou, J., et al. (2019) Viral Hepatitis B, and C: Epidemiological and Clinical Aspects at the National University Hospital Center of Cotonou. Médecine d Afrique Noire, 66, 5-12.

[7] Sylla, K., Sow, M.S., Bangoura, E., et al. (2019) Hepatitis Viral B in Penitentiary Environment in Guinea: States of Place in the Central House of Conakry. Revue Africaine de Médecine Interne, 6, 16-20.

[8] Keita, M., Fadiga, A.G., Soumah, M.M., Sylla, D., Traore, F.A., Biané, B., Tounkara, T.M., Camara, A.D., Baldé, H., Camara, A., Doumbouya, A. and Cissé, M. (2014) HIV and Hepatitis B Virus Co-Infection in the Hematology Department of the Ignace Deen National Hospital (Guinea-Conakry). Annales de Dermatologie et de Vénéréologie,142, S442. https://doi.org/10.1016/j.annder.2014.09.479

[9] Kaba, D., Diallo, M.S., et al. (2020) Prevalence of HBS Antigen in HIV-Infected People at Hôpital de Jour Donka (Guinea). Health Sciences and Disease, 21, 13-16.

[10] Baldé, N.M., Kourouma, K., et al. (2007) Clinical Characteristics of Hepatitis B, and HIV Seroprevalence in 248 Diabetics in Conakry, Guinea. Médecine d Afrique noire, 5403, 174-178.

[11] Cohen, D., Shimakawa, Y., Ndow, D., et al. (2019) Prevention of Hepatitis B Virus-Related Fibrosis and Liver Cancer in Africa the Prolifica Project. Médecinel Sciences, 35, 431-439. https://doi.org/10.1051/medsci/2019076

[12] Ahoui Apendi, C., Itoua-Ngaporo, N.A., Mongo-Onkouo, A., et al. (2020) Evaluation of Nucleoside Analogues in the Treatment of Viral Hepatitis B in Brazzaville. Health Sciences and Disease, 21, 100-103.

[13] Traore, O., Diarra, A.S., Abu, T., et al. (2018) Profile of Chronic Viral Hepatitis B in CHU Hassan II of Fez in Morocco. Journal of Liver Research, Disorders \& Therapy, 4, 181-184.

[14] Trepo, C., Bouvet, B. and Bertarnd, L. (1984) Viral Hepatitis: The Causative Agents of the Hepatitis B Virus. Encyclopédiemédico-Chirurgicale (Foie-Pancréas), 10 p.

[15] Bossali, F., Ndziessi, G., Ahoui-Apendi, C.L., Deby, G., Mimiesse, M.J.F., Ombila, J.W., Atipo-Ibara, B.I. and Ibara, J.R. (2018) Evaluation of Viral Hepatitis B Treatment in Pointe-Noire in 2016. Journal International de Médecine Clinique, 9, 513-519. https://doi.org/10.4236/ijcm.2018.96044

[16] Diallo, S., Bassène, M.L., Gueye, M.N., et al. (2018) Viral Hepatitis B: Clinical, Paraclinical and Evolutionary Features within the Hepatogastroenterology Department at the Aristid Le Dantec Hospital: About 723 Cases. The Pan African Medical Journal, 31, 82. https://doi.org/10.11604/pamj.2018.31.82.14725

[17] Rimland, D., Parkin, W.E., Miller Jr., G.B., et al. (1977) Hepatitis B Outbreak Found in Oral Surgeon. The New England Journal of Medicine, 296, 953-958. https://doi.org/10.1056/NEJM197704282961701

[18] Arboleda, M., Castilho, M.C., Fonseca, J.F., Albuquerque, B.C., Saboia, R.C. and Yoshida, C.F.T. (1995) Epidemiological Aspects of Hepatitis B and D Virus Infection in the Northern Region of Amazonas, Brazil. Transactions of the Royal Society of Tropical Medicine and Hygiene, 89, 481-483. https://doi.org/10.1016/0035-9203(95)90074-8

[19] Asian Pacific Association for the Study of the Liver (2016) Asian-Pacific Clinical 
Practice Guidelines on the Management of Hepatitis B: A 2015 Updates. Hepatology International, 10, 1-98. https://doi.org/10.1007/s12072-015-9675-4

[20] Maaref, F., et al. (2011) Prevalence of Hepatitis G, B and C Virus Infections among Positive HIV Population in a Tunisian Hospital, La Rabta, Tunis. Pathologie Biologie, 59, 213-216. https://doi.org/10.1016/j.patbio.2009.10.004

[21] Halima, S.B., Bahri, O., Maamouri, N., Cheikh, I., Alaya, N.B., Sadraoui, A., Azaiez, O., Azouz, M., Mami, N.B. and Triki, H. (2010) Serological and Molecular Expression of Hepatitis B Infection in Patients with Chronic Hepatitis C from Tunisia, North Africa. Virology Journal, 7, Article No. 229.

https://doi.org/10.1186/1743-422X-7-229

[22] Lawson-Ananissoh, L.M., Attia, K.A., Diallo, D., Doffou, S., Kissi, Y.H., Bangoura, D., Kouamé, D., Mahassadi, K.A., Yao-Bathaix, F. and Yoman, T.N. (2017) Distribution and Clinical Implications of the Genotypes of the Hepatitis B Virus in 33 Chronic Carriers of Hepatitis B Virus in Côte-d'Ivoire. Journal Africain d HépatoGastroentérologie, 11, 116-120.

https://doi.org/10.1007/s12157-017-0726-4

[23] Chen, C.J., Yang, H.I., Su, J., et al. (2006) Risk of Hepatocellular Carcinoma across a Biological Gradient of Serum Hepatitis B Virus DNA Level. JAMA, 295, 65-73. https://doi.org/10.1001/jama.295.1.65 